\title{
The role of self-monitoring in adult learning in online context
}

\author{
$M^{\text {a }}$ de Fátima Goulão*, Rebeca Cerezo Menedez ** \\ * UIEDF-UL / Universidade Aberta, Portugal \\ ** University of Oviedo, Department of Psychology, Spain
}

\begin{abstract}
This paper examines the reflexions made by a set of online students regarding the results obtained in an assessment task and its consequences for the future. The sample included 43 students in continuous assessment, from both sexes. After knowing the results they were asked to indicate the implications of this exercise to their future studies. The content analysis revealed the existence of two categories - Causality (intrinsic / extrinsic) and Influence (Generics/Specifics/No consequences) - regardless of the approach to real evaluation. The reflection that students can make about their learning process and the difficulties in developing their tasks is of great relevance to achieve success. This was evident in the analysis that our students made on the completion of the assessment work, as well as the consequences for their future study. This process of reflection and awareness in the teaching learning process is particularly relevant in online education where the role of metacognitive monitoring and control system gains a prominent role. Allowing students to reflect on these issues permits them to be more effective learners.
\end{abstract}

Keywords: metacognition; adult learning; online learning

\section{Introduction}

Technological advances have been giving a new face to distance learning systems. ICTs open new perspectives to facilitate learning. They work as tools that complement and are a real and basic support to the training system. Through the features of virtual learning environments, virtuality - eliminating barriers of time and space -, globality and the ubiquity - the campus is always with us.

This new format implies methodological, pedagogical, psychological and even emotional changes with consequent modifications in roles and functions of the actors involved in it. These new learning scenarios lead to a change of attitude and posture relative to this whole process. This change should be taken into account on both sides - learners and teachers.

Students in eLearning require greater self-direction and self-regulation to achieve their academic goals (Bol \& Garner, 2011). To lead the students to reflect on their learning strategy and tailor their metacognitive strategies to achieve success in the task is of great relevance. This means that the incorporation of ICT in the educational context, using the virtual spaces, allows a more effective response to the educational challenges by allowing using strategies and tools that best fit to the real needs of their learners. The research work of Azevedo and Cromley (2004) points to the implications that the design of virtual learning environments have on the acquisition of knowledge.

Learners who know, more appropriately, how to study and how learning occurs, i.e., have better metacognitive knowledge and learn better, when compared with those who have less metacognitive knowledge. It is therefore essential to teach learners about how they learn and identify themselves with the most effective learning strategies, so that they can improve their metacognitive judgments, as well as the selfregulation of their learning. 
Leclercq and Denis (1995) defined a good learner as a person who solves learning problems (p.155); that is a good regulator of their own learning. For them learning is a regulated process of problem solving (p.155). This process can be decomposed into six major phases and a good learner is one who can manage well each one. This process requires analyzing needs, setting goals, planning of learning strategies, executing, observing and ultimately deciding.

Hacker et al (2009) refer that learners can be agents of their own thoughts and behaviors, can monitor their knowledge or skills, establish their learning objectives, outline and control strategies / plan to achieve them, monitor progress for their possible adjustments and, finally, assess whether the objectives were achieved. All this translates into what Zimmerman (2000) calls self-regulation of behavior. According to this author the concept of self-regulation can be defined as selfgenerated thoughts, feelings and actions for attaining academics goals (Zimmerman, 1998). The key element of self-regulation is self-monitoring that involves the observation and monitoring of the performance itself, as well as its results. This in order to understand their learning process and apply these strategies in future situations, where they will prove to be adequate.

According to Serra and Metcalfe (2007) the following aspects have been associated to the concept of metacognition - knowledge about the process, about their monitoring and their control. The learning process leads to a continuous self-evaluation and a consequent decision on what to do with the information collected: What's next? What do I need to study more? Have I study this content? What strategies will be used? (Goulão, 2009).

According to Bjork, Dunlosky and Kornell (2013) for learners to become effective in the learning process, they should not only be able to assess accurately the states of their own learning, but also be able to manage it and the activities in response to such monitoring (pág.422).

By monitoring, the learner can check how his plans become actions and through the introspection, made about their achievements, learners can perceive discrepancies between what were their goals and what actually exists. The learner can thereby exercise metacognitive control, reviewing goals, plans to adapt or operations of change (Winne \& Nesbit, 2009).

According to Blakey and Spence (2000) the basic metacognitive strategies are a) to know how to relate new information with existing one, b) to know how to select the appropriate thinking strategies and c) to learn to plan, monitor and evaluate the thought processes. The reflection, in a conscious way, about the processes of learning is therefore an essential element to the development of increasingly efficient learners.

To Ertmer and Newby (1996) the expert learner is one who is aware of the specific knowledge to reactivate, the goals they have to achieve, the strategies they need to achieve them, as well as this whole process - Figure 1 .

Expert Learning

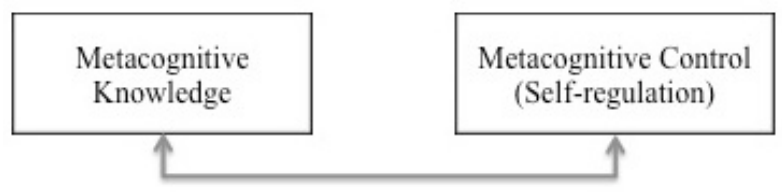

Figure1. Major components of expert learning (Ertmer \& Newby, 1996, pág. 7) 
Those learners are considered experts due to the fact that they can incorporate and implement different knowledge to improve their performance.

In online distance education, learners found more flexibility, allowing them to achieve goals that otherwise were unachievable. The acquisitions are located at different levels: concerning their formal knowledge and at the personal level, with the development of their autonomy, their critical thinking and collaborative work. This flexibility of time and space allows better management of their education formation according to their needs. In online distance education environments one of the most important roles of the teacher is as the mediator / facilitator of learning. This means that you as the teacher should aim to provide appropriate educational aid for students to develop their autonomy and their learning construction - Figure 2.

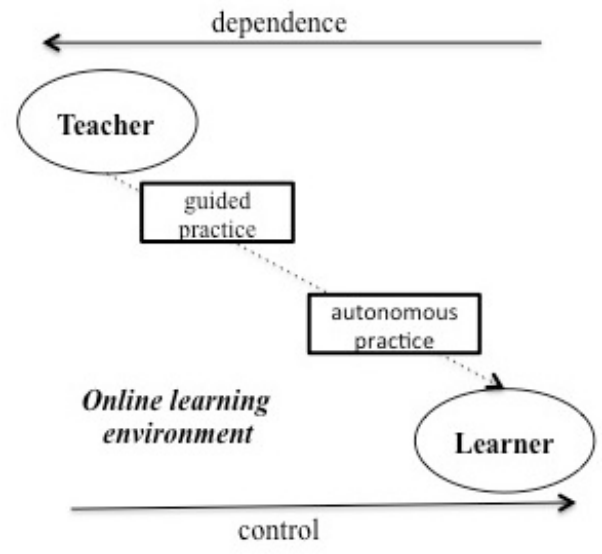

Figure 2. Methodological scenario

Thus, these new learning scenarios lead to a change of attitude and posture relative to this whole process. This change should be taken into account on both sides learners and teachers.

Learners who know, more appropriately, how to study and how learning occurs, i.e., have better metacognitive knowledge and learn better, when compared with those who have less metacognitive knowledge. It is therefore essential to teach learners about how they learn and identify themselves with the most effective learning strategies, so that they can improve their metacognitive judgments, as well as the selfregulation of their learning.

\section{Material and Methods}

\section{Objectives}

This study aims to analyze the reflexions made by a set of online students regarding the results obtained in an assessment task and its consequences for the future.

\section{Design and participants}

Data collection was made through the answers students gave to a question made after the results of their assessment were disclosure. A total of 43 students, in continuous assessment, answered the question, as volunteers.14\% were males and $86 \%$ were females. The average age of the participants was 41, ranging from 26 and 57 years old (see Table 1) one student was in his 20s, 21 students were in their 30s, 11 students were in their 40s and 9 students were in their 50s. The median age was 42. 
Table 1. Descriptive statistics of participansts’ age

\begin{tabular}{llllll}
\hline Variable & $\mathrm{N}$ & MIN & MAX & AVG & SD \\
\hline Age & 43 & 25 & 60 & 42.17 & 8.82 \\
\hline
\end{tabular}

\section{Material and procedure}

The data was collected in one curricular unit from to the first year, second semester of the degree course in Education. We have three moments of continuous assessment. Our analysis will be made only to the results obtained in the first moment.

Before starting, a message was placed in the "News" forum about the purpose of the research and requesting the participation of the students. Whenever a questionnaire was available for collecting data another message was placed in the forum requesting the response of students.

The data collection was done in three stages. Before completing their assessment test, students were asked to indicate what grade they expected to obtain (Predicted scores). Immediately after finishing their test, they were asked again to indicate the grade they expected to obtain (Postdicted Score). Finally, after the results came out students were asked to indicate whether their real grades, were higher, lower or equal compared with their prediction. Furthermore, they were asked about this and what would be the implications for their study method. Our analysis focus was on this last phase.

\section{Data analyses}

We proceeded to the analysis of participants' responses according to how the questions were asked. It was the purpose of this research to examine the justifications given by this online students regarding the results obtained in the first continuos assessment task and how this fact will affect their study process in the future. To analyse their responses, we used content analysis. In the answers given by the students could be found more than one category or sub-category. For this reason the number of occurrences by category be more than the number of participants in the study.

\section{Results and Discussion}

The content analysis of the answers given by the students to the question after the results came out (real grades) allowed us to establish the following categories and sub-categories, regardless of the dimension in question - Table 2

Table 2. Content analysis results: Categories and sub-categories

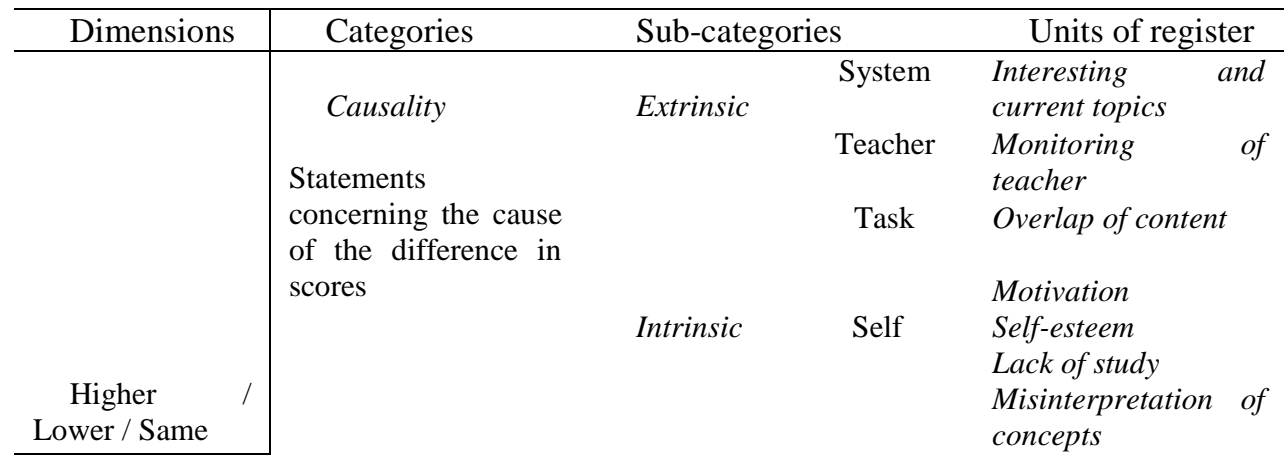




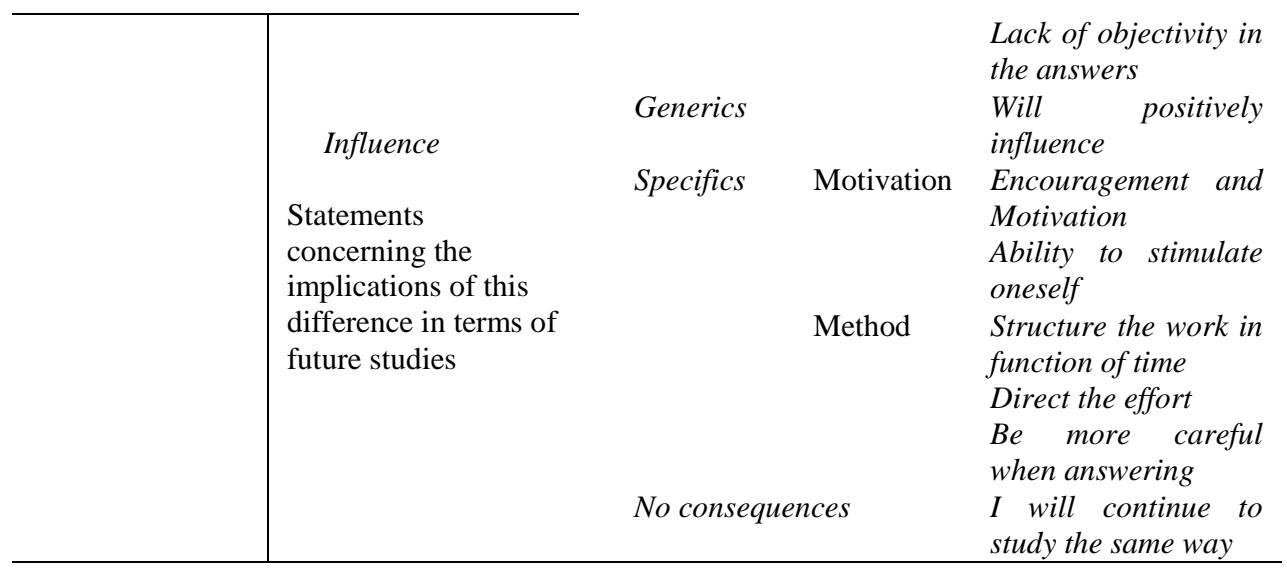

The indication of a Higher, Lower or Same classification, comparing the scores obtained with the ones predicted was not clear. For that reason, the content analysis presented in this paper includes the responses in global terms. The Dimension has not proved to be a suitable descriptor. The following results refer to the analysis of frequency distribution taking into account the categories and sub-categories. Table 3 shows the results found in the category Causality.

Table 3. Categorie Causality: Number of occurrences of sub-categories

\begin{tabular}{|c|c|c|c|c|c|}
\hline & \multicolumn{4}{|c|}{ Sub-categories } & $\mathbf{N}$ \\
\hline \multirow{8}{*}{ 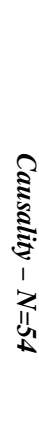 } & & System & & & 2 \\
\hline & Extrinsic & Teacher & & & 2 \\
\hline & Total $=6$ & Task & & & 2 \\
\hline & \multicolumn{4}{|c|}{ Individual characteristics } & 12 \\
\hline & \multirow{4}{*}{$\begin{array}{l}\text { Intrinsic } \\
\text { Total = } \\
\mathbf{4 8}\end{array}$} & \multirow[t]{4}{*}{ Self } & \multirow{2}{*}{$\begin{array}{l}\text { Performance } \\
\text { (Total = 19) }\end{array}$} & Positive nature & 6 \\
\hline & & & & Negative nature & 13 \\
\hline & & & \multirow{2}{*}{$\begin{array}{l}\text { Organization } \\
\text { / Planning } \\
(\text { Total }=16)\end{array}$} & Positive nature & 10 \\
\hline & & & & Negative nature & 6 \\
\hline
\end{tabular}

As it can be seen in Table 3, the highest number of occurrences that justify the classifications obtained is at the level of the subject himself. These may refer to more individual characteristics, such as motivation, self-esteem and lack of confidence in the competencies, but also on aspects that may be more controllable by the student. This level involves the way the subject feels within the assessment task, such as an incorrect interpretation of questions, a difficulty in understanding some questions. Finally, we find the issues related to the preparation for the assessment task. These refer to the organization and planning of the study itself.

We turn now to the presentation of the results concerning the influence for future study situations. - Table 4 
Table 4. Categories Influence: $\mathrm{N}^{\mathrm{o}}$ of occurrences of sub-categories

\begin{tabular}{|c|c|c|c|c|}
\hline \multirow{6}{*}{ 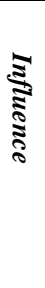 } & \multicolumn{3}{|l|}{ Sub-categories } & \multirow[t]{2}{*}{$\mathbf{N}$} \\
\hline & Generics & & & \\
\hline & & Motivation & & 10 \\
\hline & Specifics & Method & Performance & 8 \\
\hline & & (Total=17) & Organization & 9 \\
\hline & No consequences & & & 1 \\
\hline
\end{tabular}

The largest number of occurrences indicates that the influence will be felt more deeply at the level of motivation and method of work. This is particularly true in regards to issues relating to the method of organizing tasks in either study, or in they performance in the next assessment task.

\section{Conclusions}

In this paper, we set out to find out and work on the reflections that of a group of online learning students has made about their performance in a very specific assessment task. In a first analysis of the responses we observed that these reflections involve mainly factors related to the students or factors that they can control.

The analysis of the answers seems to indicate an emphasis on the concern with issues related to organization and planning of the study. This is evident in both the causes and the conditions to be considered in a future study. However, reading these results should be done in a careful manner and taking into account that the students participated in this study voluntarily and that the majority considered to have a good rating taking as reference the statement given in the previous phase of the study.

From our point of view is important to know the aspects that are taken into account and valued by students to have a good performance. These elements allow us to organize tasks and outline strategies to help students find their own strategies for monitoring and self-regulation of learning, becoming increasingly autonomous and thereby achieving a deeper level of learning. The knowledge that each person has in dealing with learning activities, becomes a powerful tool nowadays (Bjork, Dunlosky \& Kornell, 2013). The understanding of learning activities and associated processes promotes understanding, retention and transfer of learning.

From the point of view of Goulão and Cerezo (2015) to develop self-regulatory competence of students is not only very important to help them achieve success now, but also to ensure future successes. Actions relating to the control of performance have a critical role in the self-regulatory process leading to a monitoring process of learning by the students. This action control allows them to not only detect the weaknesses of the learning process, but also alert to the effectiveness of learning strategies that are being used. (p. 1907).

According to Ertmer and Newby (1996) reflection on the learning process is considered as an essential ingredient to develop more effective learners. In this sense we believe it is important to find strategies that help students monitor their own learning process. This monitoring is a complex process that involves understanding what you're doing, where does that fit into the sequence of the task and also the anticipation and planning of steps to follow. All this happens during the actual act of learning. For Phelp, Hase and Ellis (2001) in the context of rapid transformation, with 'capable' learners, metacognitive strategies provide great advantages and can be 
considered more important than some skills. In this sense the teacher should provide strategies to help the learner become an "expert learner".

Self-regulation plays an extremely relevant role in the learning process of students in general. With regard to distance learning online these processes retains relevance. The self-regulatory capacity of learning is an important factor to overcome procrastination. This importance is increased when we are in online contexts, to provide information to teachers to seek to develop strategies that help reduce procrastination and thus make them more self-regulated learners. Moreover, in the online distance education, with adult learners, when placing the emphasis on the autonomy of the same is necessary they are holders to these competencies to enable them to analyze and understand their learning processes with a view to meaningful learning.

\section{References}

Azevedo,R. \& Cromley, J.G., (2004). Does training on self-regulated learning facilitate student's learning with hypermedia?.Journal of Educational Psychology, 96(3), 523-535

Bjork, R.A., Dunlosky,J. \& Kornell,N. (2013). Self-Regulated Learning: Beliefs, Techniques and Illusions. Annual Review of Psychology, 64,417-444

Blakey, E., \& Spence, S. (2000). Developing metacognition. Syracuse, NY: ERIC Clearinghouse on Information Resources. Retrieved from http://ericae.net/edo/ED327218.htm

Bol,L \& Garner,J.K. (2011). Challenges in supporting self-regulation in distance education environments. Journal Computer High Education, 23, $104-123$

Ertmer, P. A., \& Newby, T. J. (1996). The expert learner: Strategic, self-regulated and reflective. Instructional Science, 24, 1-24.

Goulão, $M^{a}$ F. (2009). Metacognition, Learning Styles and Distance Education. In Subhi-Yamin,T.(Eds), Excellence in Education 2008: Future Minds and Creativity. Proceedings of the Annual Conference of the International Centre for Innovation in Education (pp.224 - 232). ICIE: Ulm- Germany

Goulão, M ${ }^{\mathrm{a} F}$. \& Cerezo, R. (2015). Learner autonomy and self-regulation in eLearning. Procedia - Social and Behavioral Sciences, 174, 1900 - 1907

Hacker, D.J. et al (2009). Metacognition in Education: A focus on Calibration. In Dunlosky,J. \& Bjork,R. (Eds.), Handbook of Memory and Metacognition (pp.149). Mahwah, NJ: Lawrence Erlbaum Associates.

Leclercq, D. \& Denis,B. (1995).Autoformation \& Hypermédias: Qu'est-ce qu'un bon auto-apprenant ?. in Pratiques d'autoformation et d'aide à l'autoformation, Actas do Deuxième colloque européen sur l'autoformation, USTL / CUEEP, pp.155 161

Phelp,R., Ellis,A. \& Hase,S. (2001, December). The role of metacognitive and reflective learning process in developing capable computer users. In in $G$ Kennedy, M Keppell, C McNaught \& $\mathrm{T}$ Petrovic (Eds), Meeting at the crossroads: proceedings of the 18th Annual Conference of the Australasian Society for Computers in Learning in Tertiary Education (ASCILITE) (pp. 481490). University of Melbourne, Biomedical Multimedia Unit, University of Melbourne, Melbourne, Vic. 
Serra, M.J. \& Metalfe,J. (2009). Effective Implementation of Metacognition. In Hacker,D.J. Dunlosky,J. \& Graesser, A.C. (Eds.). Handbook of Metacognition in Education (pp.278-298). New York: Routledge.

Winne,P.H. \& Nesbit,J.C.(2009). Supporting Self-Regulated Learning with Cognitive Tools. In Hacker, D., Dunlosky,J. \& Graesser, A. (Eds). Handbook of Metacognition in Education (pp.259-277). New Yok: Routledge

Zimmerman (2000). Attaining self-regulation: A social cognitive perspective. In Boekaerts,M., Pintrich, P.R. \& Zinder, M. (Eds), Handbook of Sel-Regulation (pp.13-29). San Diego, CA:Academic Press

Zimmerman, B. (1998). Academic studying and the development of personal skill: a self-regulatory perspective. Educational Psychologist, 33(2/3), 73-86 